\title{
Influence of Friction Stir Welding on Mechanical Properties of Butt Joints of AZ61 Magnesium Alloy
}

\author{
Seung-Ju Sun, ${ }^{1}$ Jung-Seok Kim, ${ }^{1}$ Woo Geun Lee, ${ }^{1}$ Jae-Yong Lim, ${ }^{2}$ \\ Yohan Go, ${ }^{3}$ and Young Min Kim $^{3,4}$ \\ ${ }^{1}$ New Transportation Systems Research Center, Korea Railroad Research Institute, Uiwang, Republic of Korea \\ ${ }^{2}$ School of Mechanical Engineering, Daegu University, Gyeongsan, Republic of Korea \\ ${ }^{3}$ Advanced Materials Engineering, University of Science and Technology, Daejeon, Republic of Korea \\ ${ }^{4}$ Materials Implementation Department, Korea Institute of Materials Science, Changwon, Republic of Korea
}

Correspondence should be addressed to Jung-Seok Kim; jskim@krri.re.kr

Received 15 March 2017; Revised 7 June 2017; Accepted 27 June 2017; Published 3 August 2017

Academic Editor: Bernd-Arno Behrens

Copyright (C) 2017 Seung-Ju Sun et al. This is an open access article distributed under the Creative Commons Attribution License, which permits unrestricted use, distribution, and reproduction in any medium, provided the original work is properly cited.

\begin{abstract}
In this study, the effect of heat input on the mechanical properties and fracture behaviors of AZ61 magnesium alloy joints has been studied. Magnesium alloy AZ61 plates with thickness of $5 \mathrm{~mm}$ were welded at different ratios of tool rotational speed to welding speed $(\omega / \nu)$. The average ultimate tensile strength of all weld conditions satisfying a $\omega / \nu$ ratio of 3 reached $100 \%$ of the strength of the base material. Fractures occurred at the interface between the thermomechanical affected zone at advancing side and the stir zone in all welded specimens. From the scanning electron microscope and electron backscatter diffraction analysis, it was determined that the interface between the thermomechanical affected zone and the stir zone, which is the region where the grain orientation changes, was the weakest part; the advancing side region was relatively weaker than the retreating side region because the grain orientation change occurred more dramatically in the advancing side region.
\end{abstract}

\section{Introduction}

To overcome environmental and energy efficiency problems, weight reduction of transportation vehicles is being actively researched $[1,2]$. There are several ways to achieve lightweight vehicles: (1) optimization design to reduce the thickness of the target structures $[3,4],(2)$ reduction of the number of parts by applying multifunctional materials $[1,5-8]$, and (3) replacement of vehicle structures with lightweight materials. However, both methods (1) and (2) have reached their limits and the next step will require replacement of vehicle structures with lightweight materials.

The specific gravity of magnesium, the lightest of all commonly used metals, is 1.74 , just $2 / 3$ that of aluminum, which is 2.56 . Hence, magnesium alloys, the use of which can reduce both emissions of greenhouse gas and fuel consumption $[9,10]$, are increasingly being used in the transportation. It is expected that this metal can lead to remarkable improvements in vehicle structures because it also has a number of other desirable advantages, like high specific strength, high specific stiffness, better damping characteristics than aluminum, and so on. Due to these advantages, studies on the joining of magnesium have been actively conducted. Welding technology is an essential factor for joining metals. In the case of conventional fusion welding, it is difficult to secure superb mechanical properties due to various defects such as distortion, solidification cracking, and liquation cracking due to the high temperature of the weld. In order to be free of these defects, a solid-state welding process has been attempted recently. Friction stir welding (FSW), a solid-state joining method [11], can eliminate several challenges associated with conventional fusion welding [11-13]. The magnesium alloy, due to its strong reactivity with oxygen, is preferred to weld below its melting point. Therefore, FSW is the most suitable welding technique for magnesium alloys.

In FSW, it is very important to understand the relationship between the heat input and the soundness in the welded zone. Insufficient heat input causes tunnel, porosity, 

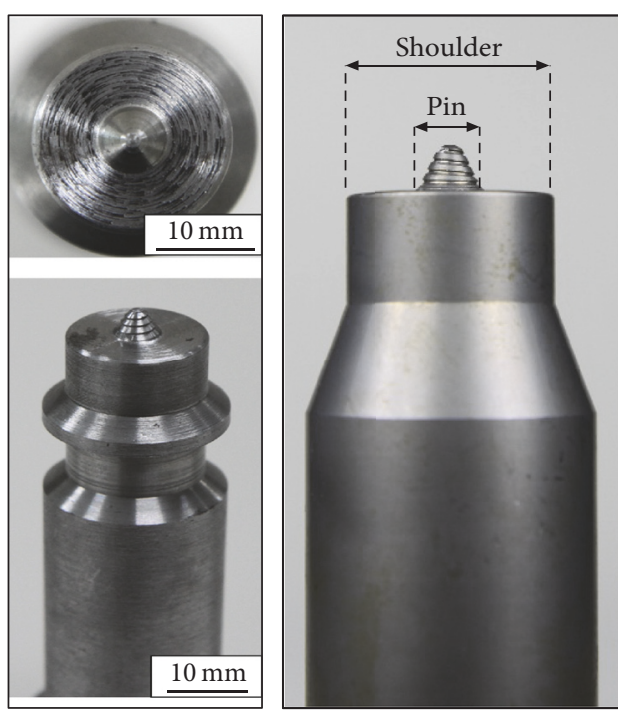

(a)
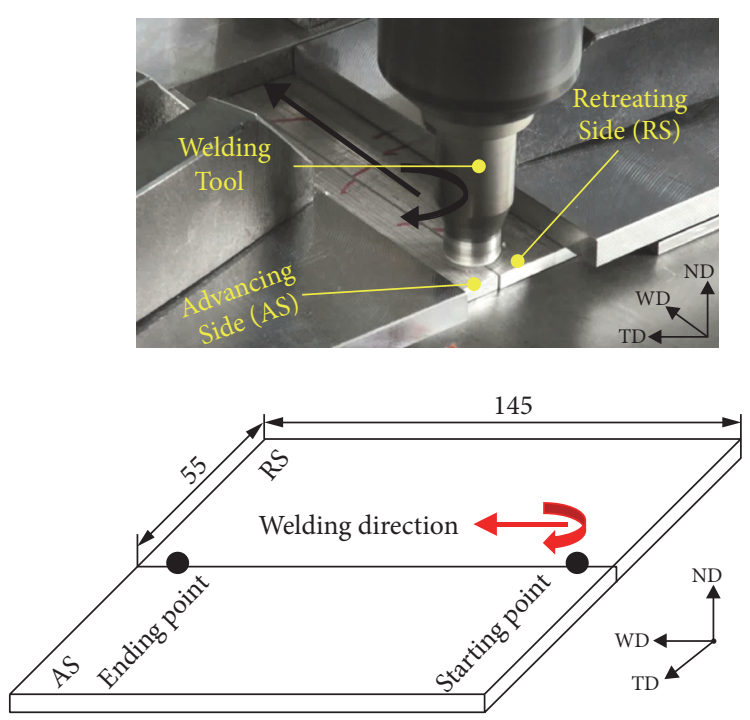

(b)

FIGURE 1: (a) Schematic illustration of FSW process; (b) actual welding tool with threaded taper pin (all dimensions are in mm, WD (welding direction), ND (normal direction), and TD (transverse direction)).

and kissing bond defects [14-17]. Excessive heat input also can lead to some defects such as large amounts flash (burr) $[18-20]$ and oxides [21, 22].

Frigaard et al. [23] proposed an equation to describe the heat input during FSW. The complex equation proposed by Frigaard et al. can be simply expressed [24] as the following equation (with constant pressure):

$$
\mathrm{Q} \propto \frac{\omega}{v},
$$

where $Q[\mathrm{~J} / \mathrm{mm}]$ is the total heat input, $v[\mathrm{~mm} / \mathrm{min}]$ is the welding speed, and $\omega[\mathrm{rpm}]$ is the rotational speed of welding tool. This equation shows how the rotational speed and welding speed affect the heat input in the FSW process. It can be inferred that increasing the rotational speed at a constant welding speed or decreasing the welding speed at a constant rotational speed can lead to higher total heat input. Thus, it is very important to control the rotational and welding speeds to ensure proper heat input levels.

Most studies on the welding of magnesium alloys have been focused on AZ31 magnesium alloys, and joint efficiency is determined by applying arbitrary tool rotational speed and welding speed. Among the magnesium alloys, AZ61 magnesium alloy is more suitable for structural purposes than AZ31 because of its excellent strength and because its weldability is similar to that of AZ31. However, few studies have been performed on FSW of AZ61 magnesium alloy [25].

The aim of this study is to evaluate the weldability of AZ61 magnesium alloys based on the rotational speed as determined by the welding speed ratio and to analyze the fracture behavior of AZ61 magnesium alloy joints.

\section{Experimental}

In this study, AZ61 magnesium alloy extruded plates $(55 \mathrm{~W}$ $\times 145 \mathrm{~L} \times 5 \mathrm{~T} \mathrm{~mm}^{3}$ ) were used as the base material. Table 1
TABLE 1: Chemical composition of AZ61 (wt.\%).

\begin{tabular}{lcccccc}
\hline $\mathrm{Al}$ & $\mathrm{Cu}$ & $\mathrm{Zn}$ & $\mathrm{Mn}$ & $\mathrm{Si}$ & $\mathrm{Fe}$ & $\mathrm{Mg}$ \\
\hline 6.75 & 0.97 & 0.97 & 0.23 & 0.018 & 0.0049 & Remains \\
\hline
\end{tabular}

shows the chemical compositions of these materials. The tool for welding was made of SKD61 steel and composed of a concave shoulder with a diameter of $18 \mathrm{~mm}$; it had a tapered cylindrical threaded pin with an upper diameter of $6 \mathrm{~mm}$, a lower diameter of $1.8 \mathrm{~mm}$, and a height of $4.5 \mathrm{~mm}$, as shown in Figure 1 . The tapered threaded pin usually induces plastic flow in the vertical direction and reduces the traverse load. Thus, the tapered threaded pin can improve weldability and enable faster tool travel speeds [11, 26]. In addition, the tapered threaded shaped pin profile, which is used in the common industrial applications, can be expected to be a more practical study.

In this study, two magnesium plates were butt-welded using FSW; the welding was conducted along the extrusion direction of the AZ61 magnesium alloy, as shown in Figure 1(a). The load applied to the friction stir welding was $8.6 \mathrm{kN}$; the tilting angle of the welding tool to the workpiece was set to $2^{\circ}$. At $\omega / \nu$ ratios of 2 and 3, FSW with various welding conditions (Table 2) was carried out and the mechanical properties and microstructure of the butt joints were evaluated. (For convenience of description, the $\omega / \nu$ ratios of 2 and 3 are expressed as $\omega / \nu=2,3$ in the following text.)

For the microstructure and mechanical properties evaluation, the samples were sectioned perpendicular to the welding direction and tensile specimens were evaluated using the ASTM E8. (Figure 2). The equipment used for the tensile test was an Instron 5982 model at a crosshead speed of $1.5 \mathrm{~mm} / \mathrm{min}$. A Vickers hardness test was performed to 
TABLE 2: Welding parameters satisfying $\omega / \nu$ ratios 2 and 3.

\begin{tabular}{|c|c|c|c|c|c|}
\hline Heat input $(Q)$ & ratio Welding condition & Rotational speed $(\omega)[\mathrm{rpm}]$ & Welding speed $(\nu)[\mathrm{mm} / \mathrm{min}]$ & Axial force $[\mathrm{kN}]$ & Plunge depth [mm] \\
\hline \multirow{4}{*}{$\omega / \nu=2$} & (a) & 400 & 200 & \multirow{8}{*}{8.6} & \multirow{8}{*}{4.8} \\
\hline & (b) & 600 & 300 & & \\
\hline & (c) & 800 & 400 & & \\
\hline & (d) & 1000 & 500 & & \\
\hline \multirow{4}{*}{$\omega / \nu=3$} & (e) & 600 & 200 & & \\
\hline & (f) & 900 & 300 & & \\
\hline & (g) & 1200 & 400 & & \\
\hline & (h) & 1500 & 500 & & \\
\hline
\end{tabular}
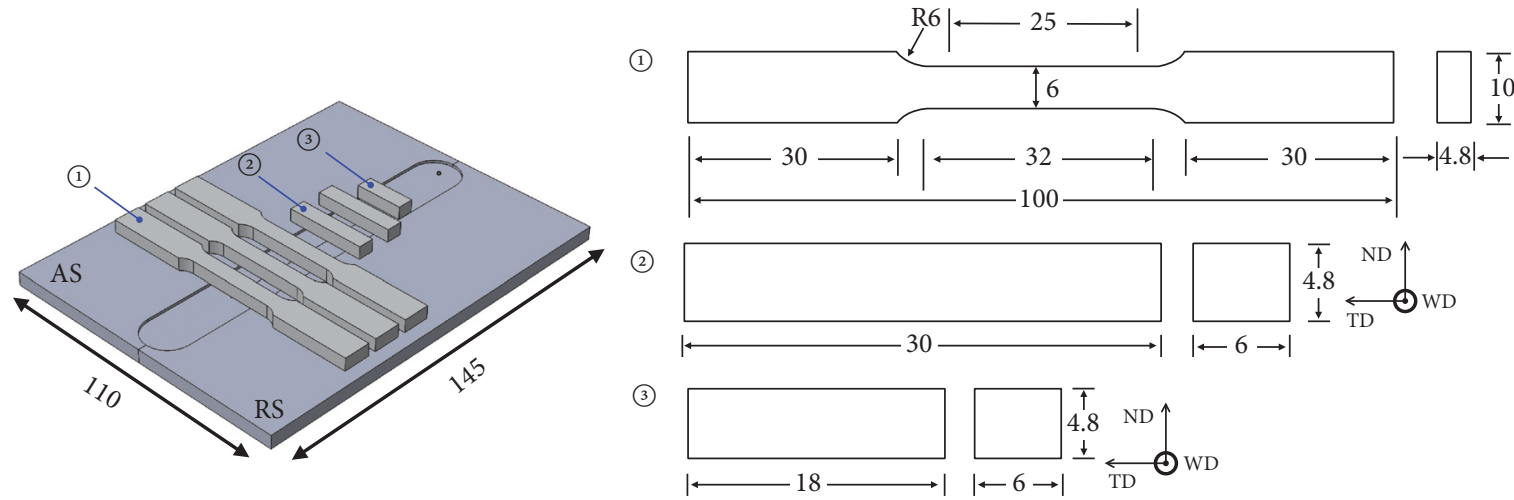

Figure 2: Test specimen shape of AZ61 Mg alloy (all dimensions are in mm). (1) Tensile specimen, (2) specimen for microstructure and hardness analysis, and (3) specimen for electron backscatter diffraction analysis.

measure the indentation resistance of the cross section. For the hardness test, an HM-112 model of Mitutoyo was used. The applied load for the test was $2 \mathrm{kgf}$, the duration was 10 seconds, and the distance between measuring points was $0.5 \mathrm{~mm}$.

The microstructure, fracture surface, and grain orientation of the specimens were observed and analyzed by optical microscope (OM, Olympus GX51), scanning electron microscope (SEM, JEOL JSM-6610LV), and electron backscattered diffraction (EBSD, JEOL JSM-6610LV), respectively. Etching for the cross-sectional surface was carried out using an acetic picric etchant ( $3 \mathrm{~g}$ picric acid $+10 \mathrm{ml}$ acetic acid $+10 \mathrm{ml}$ water $+100 \mathrm{ml}$ ethanol).

\section{Results and Discussion}

3.1. Macroscopic/Microscopic Analysis. No defects were found in the welding surface for all welding conditions regardless of the heat input values. For more detailed investigation, the cross-sections of the welding regions were observed using an optical microscope (OM). The cross-sectional views of the welded specimens at the ratio $\omega / \nu=2$ are shown in Figure 3. These images reveal that defects were found in all the welding specimens. The defects marked with white arrows were considered to be tunnel defects distributed along the welding direction and were commonly formed at the bottom of the welding region between the stir zone (SZ) and the rest of the material located on the advancing side (AS) $[17,20]$.
Generation of such defects as those observed in the welded regions was found to depend on the quantity of the heat input. Insufficient heat input usually causes cavity defects as well as tunnel defects, but cavity defects were not found in this study. These defects are one of the main factors that deteriorate the mechanical properties of the joints. Chen et al. [27] reported that the problems of tunnel and cavity defects can be solved by generating more plastic flow. Increasing the rotational speed of the tool or lowering the welding speed in the friction stir welding process can cause more plastic flow due to the heat generated by the friction and metal flow by the stirring action of the tool. In Table 3, it can be seen that when the welding speed was lowered from $300 \mathrm{~mm} / \mathrm{min}$ (welding condition (b)) to $200 \mathrm{~mm} / \mathrm{min}$ (welding condition (e)) at the same tool rotational speed, the defects were eliminated. Contrary to the case in which the tool rotational speed was fixed, the same results were obtained, in which no defects were found when the rotational speed was increased under a constant welding speed. The cross-sectional macrographs of the welded specimens at the ratio of $\omega / \nu=3$ are shown in Figure 3. Unlike the case of the ratio of $\omega / \nu=2$, no defects were observed under all welding conditions. As mentioned above, insufficient heat input can lead to tunnel defects and cavity defects. In contrast, excessive heat input can lead to the formation of oxides [21, 22] or large amounts of flash [18-20]. As for flash defects, the rubbing action of the FSW tool causes softening of the region on both sides, and the materials within the friction stir welded region are extruded 
$\omega / v=2$

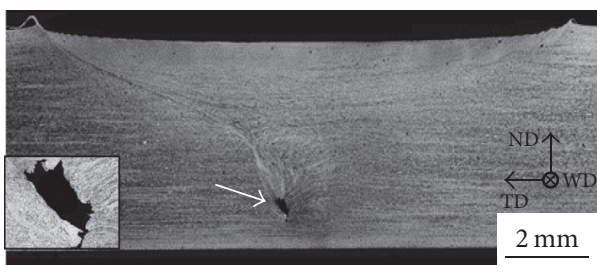

$400 \mathrm{rpm} \_200 \mathrm{~mm} / \mathrm{min}$

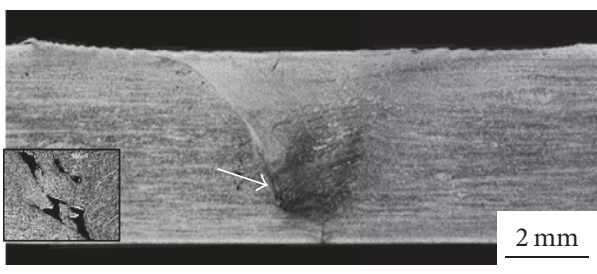

800 rpm_ $400 \mathrm{~mm} / \mathrm{min}$

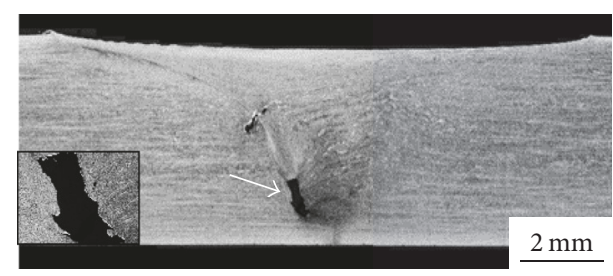

$600 \mathrm{rpm} \_300 \mathrm{~mm} / \mathrm{min}$

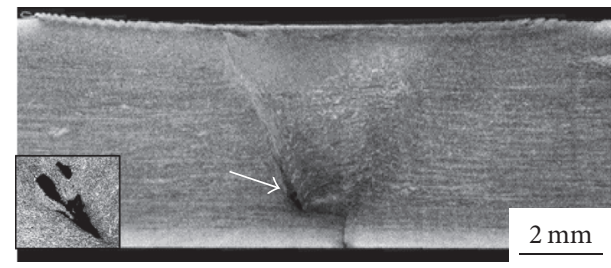

1000 rpm_500 mm/min

$\omega / v=3$

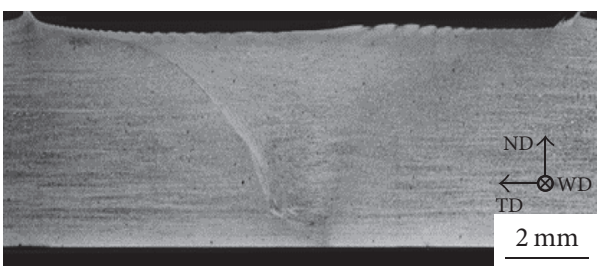

$600 \mathrm{rpm} \_200 \mathrm{~mm} / \mathrm{min}$

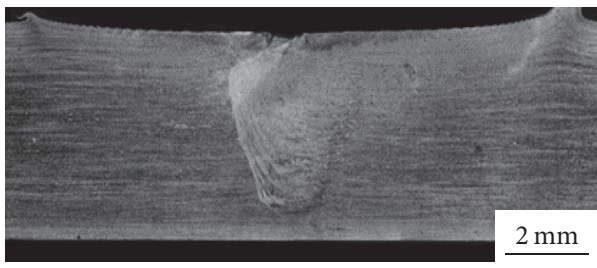

1200 rpm_400 $\mathrm{mm} / \mathrm{min}$

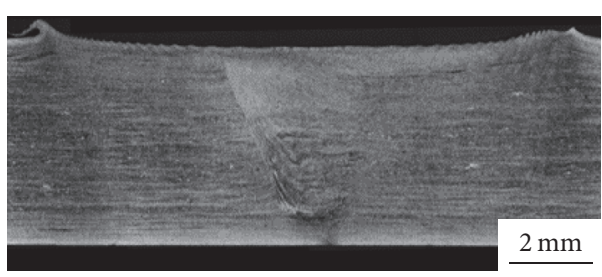

$900 \mathrm{rpm} \_300 \mathrm{~mm} / \mathrm{min}$

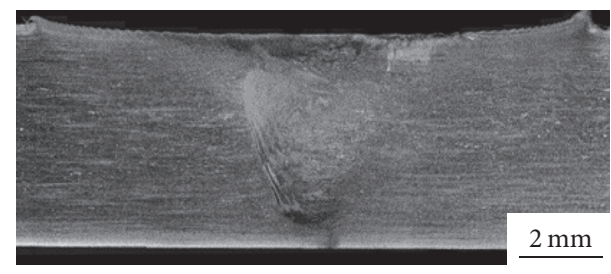

1500 rpm_500 mm/min

FIGURE 3: Cross-sectional macrographs of friction stir welded region (white arrows indicate defects).

TABLE 3: Mechanical properties of base material and of FSW AZ61 joints.

\begin{tabular}{|c|c|c|c|c|c|}
\hline Heat input $(Q)$ ratio & Welding condition & UTS [MPa] & $\mathrm{YS}$ [MPa] & El. $[\mathrm{MPa}]$ & Joint efficiency [\%] \\
\hline- & Base material & 289.0 & 202.3 & 19.8 & 100 \\
\hline \multirow{5}{*}{$\omega / \nu=2$} & (a) & 251.4 & 171.7 & 5.6 & 87.0 \\
\hline & (b) & 229.3 & 180.7 & 2.5 & 79.3 \\
\hline & (c) & 232.1 & 179.4 & 2.4 & 80.3 \\
\hline & (d) & 266.0 & 176.0 & 4.7 & 92.0 \\
\hline & Aver. & $244.7 \pm 17.3$ & $177.0 \pm 4.0$ & $3.8 \pm 1.6$ & 84.7 \\
\hline \multirow{5}{*}{$\omega / \nu=3$} & (e) & 283.6 & 169.1 & 10.0 & 98.1 \\
\hline & (f) & 291.4 & 169.4 & 12.5 & 100.8 \\
\hline & (g) & 295.9 & 173.7 & 12.0 & 102.4 \\
\hline & (h) & 294.3 & 171.8 & 13.4 & 101.8 \\
\hline & Aver. & $291.3 \pm 5.4$ & $171.0 \pm 2.2$ & $12.0 \pm 1.4$ & 100.8 \\
\hline
\end{tabular}

UTS (ultimate tensile strength), YS (yield strength), and El. (elongation). 
or expelled along the peripheral welding zone on the surface during welding due to the stirring action of the tool. As a result, the thickness of the friction stir welds becomes thinner than that of the base material, which not only is a potential cause of deterioration of the mechanical properties, but also requires additional inspection to determine the dimensions of welded region. Therefore, proper control of the rotational speed of the tool and the welding speed is essential to avoid defects.

The grain size of the SZs is also shown in Figure 4 for $\omega / \nu=2,3$. The grain size of $\omega / \nu=2$ condition was finer than that of base material, which was $3.87 \mu \mathrm{m}$. On the other hand, for $\omega / \nu=3$, the grain size was larger than the base material's. And, with increasing of the $\omega / v$ ratio from 2 to 3 , the grain size increased from about 3.7 to 4.2 in the $\mathrm{SZ}$ due to increased heat input. This means that increasing the heat input causes grain growth. Some papers [28-30] have mentioned this phenomenon, as follows. In the friction stir welding process, generally, temperatures which were applied to the SZ become higher than the recrystallization temperature and lower than the melting point. The grains in the SZ undergo dynamic recrystallization due to the stirring action and high temperature, and new microstructures are formed in the SZ. In this process, greater heat input to the SZ leads to a coarsening of the recrystallized grains. Therefore, larger grains were observed in the welded region at the ratio of $\omega / \nu=3$.

3.2. Mechanical Properties. Table 3 shows the results of the tensile test for the welded joints for the ratio of $\omega / \nu=2$ and 3. In the case of the ratio of $\omega / \nu=2$, welding condition (d) showed a maximum joint efficiency of $92.0 \%$. In this study, the joint efficiency was defined as the ratio of the ultimate tensile strength (UTS) of the welding region to the UTS of base material. In contrast, welding condition (b) showed the worst joint efficiency of $79.3 \%$. For the $\omega / \nu=2$ condition, the average joint efficiency was $84.7 \%$. In case of the ratio of $\omega / \nu=$ 3 , welding condition $(\mathrm{g})$ showed the best joint efficiency of $102.4 \%$. The worst condition was welding condition (e), with a joint efficiency of $98.1 \%$. For the $\omega / \nu=3$ condition, the average joint efficiency was $100.8 \%$. However, in the case of the ratio of $\omega / \nu=3$, the yield strength was slightly lower even though the average ultimate tensile strength and elongation were higher than those values for the ratio $\omega / \nu=$ 2. The yield strengths are related to the heat input near the welded region and to the grain size of SZ. In the welding process, increasing heat input can make material of welding region softer [31], resulting in a slight decrease of the yield strength. Considering the microstructural aspect, the lack of heat input has a greater influence on grain refinement by the welding tool. Given enough energy from the outside, such as stress and thermal stimulation, dislocations will easily move throughout the crystalline grains, resulting in permanent distortion of the grain itself. This will be reflected in plastic deformation of the material. However, once the dislocation reaches the grain boundaries, it can no longer move [32]. In other words, the grain boundaries inhibit movement of dislocations. And increasing the amount of grain boundaries by making the grain as fine as possible is one way to improve the strength of the material. Thus, in the case of the ratio of $\omega / \nu=2$, it is considered that the yield strength was higher since it had a relatively lower heat input and contains finer grains.

The hardness distributions of the welded region at $\omega / \nu=$ 3 are shown in Figure 5. The hardness was measured across the mid-thickness of the welded specimens. The average hardness value of the SZ was in the range of $66.2-68.1 \mathrm{Hv}$, which is slightly lower or similar to the hardness of the base material $(68.7 \mathrm{Hv})$. Similar results were found by Park et al. [33] for the FSW of AZ61 magnesium alloy. The hardness of the FSWed region follows the Hall-Petch relationship, as decreasing grain size with hardness increases. In this study, the hardness value of SZs is similar to the hardness of the base material because there is no significant difference between grain size of SZs and grain size of base material (Figure 6(a)). On the other hand, according to some literatures [34-37] for FSWed aluminum alloy (2000, 6000 series), the hardness of SZs decreased about $20-45 \%$ compared with the hardness value of the base material. These results of hardness dropping imply that there is vulnerable to fracture at that location. Thus, magnesium alloys with no significant dropping in hardness are more suitable for FSW. There was no remarkable feature in the overall hardness profiles in Figure 5. However, in all the welding conditions that satisfy $\omega / \nu=3$, the hardness slightly decreased temporarily in the $1 \mathrm{~mm}-3 \mathrm{~mm}$ of the AS region; then, the hardness tended to recover to the original level in the SZ. The microstructure of the thermomechanical affected zone (TMAZ) was observed to confirm that the region where the hardness temporarily decreased corresponds to TMAZ (Figure 6(b)). The grain size of TMAZ is $4.29 \mu \mathrm{m}$, which is larger than the grain size $(3.82 \mu \mathrm{m})$ of SZ at $1500 \mathrm{rpm}-500 \mathrm{~mm} / \mathrm{min}$, but it is smaller than the grain size $(4.47 \mu \mathrm{m})$ of SZ at $600 \mathrm{rpm} \_200 \mathrm{~mm} / \mathrm{min}$ welding condition. As mentioned above, since the hardness depends on the grain size, so the hardness of TMAZ should be similar to the hardness of SZ at $600 \mathrm{rpm} \_200 \mathrm{~mm} / \mathrm{min}$ welding condition. In addition, when the fracture location and hardness were compared in Figure 7, the region where the hardness temporarily decreased was the same as the part of the outer edge of SZ. Therefore, the region where the hardness temporarily decreases can be judged as the interface between SZ and TMAZ. Since the hardness profiles of magnesium alloys are uneven, it is difficult to notice easily the tendency to decrease slightly in hardness profiles. In the literature [38] for FSWed AZ31 magnesium alloys, it is stated that, in the hardness profiles, there is no known lowest hardness region. However, it is observed that the hardness decreases slightly between SZ and TMAZ regardless of the welding conditions. In order to investigate the relation between this tendency and the fracture behavior, the contents related to fracturing are discussed in Sections 3.3 and 3.4.

3.3. Fracture Feature. The fractured specimens at $\omega / \nu=2$ and 3 are shown in Table 4 . The fracturing of all kinds of specimens occurred in a region between 1 and $4 \mathrm{~mm}$ from the center of specimen to the AS region regardless of the heat input ratio. The fracture behavior of the $\omega / v=3$ condition was the same as that of the $\omega / \nu=2$ condition, even though 
$\omega / v=2$

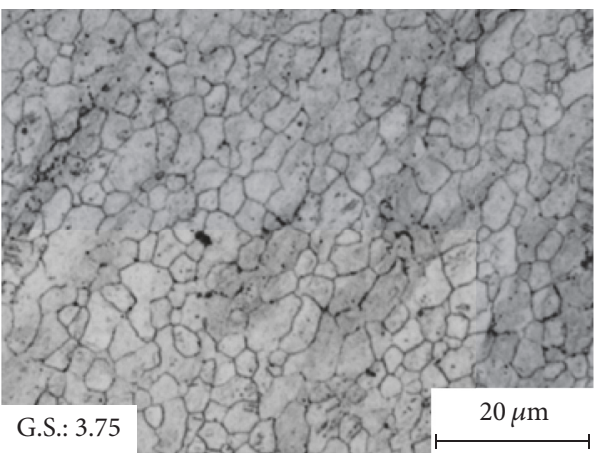

400 rpm_200 mm/min

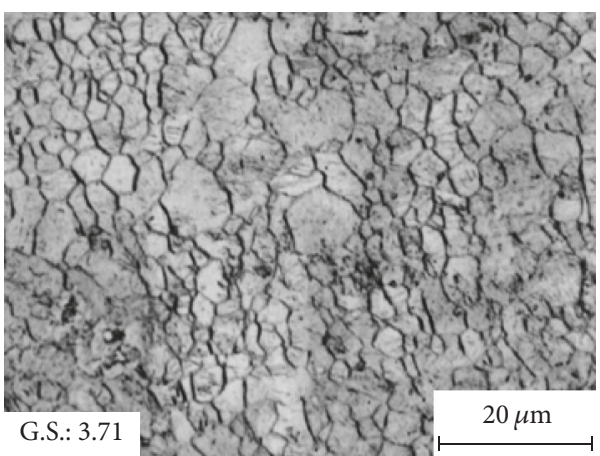

800 rpm_ $400 \mathrm{~mm} / \mathrm{min}$

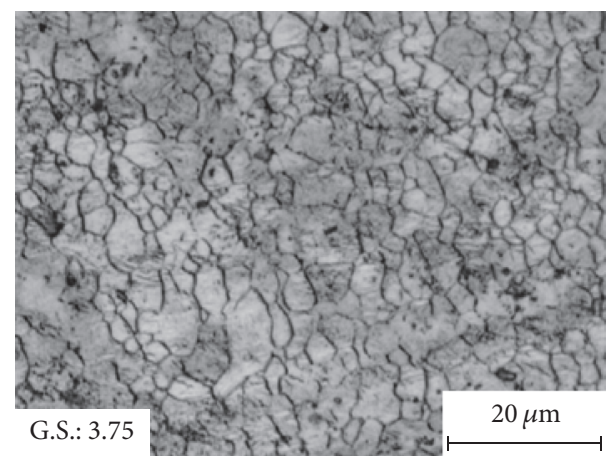

$600 \mathrm{rpm} \_300 \mathrm{~mm} / \mathrm{min}$

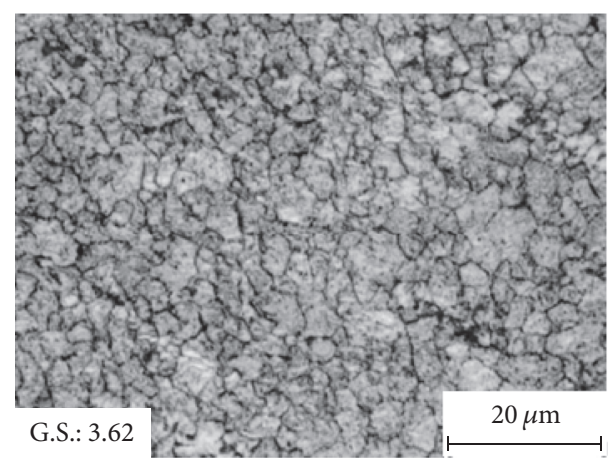

1000 rpm_500 mm/min

$\omega / v=3$

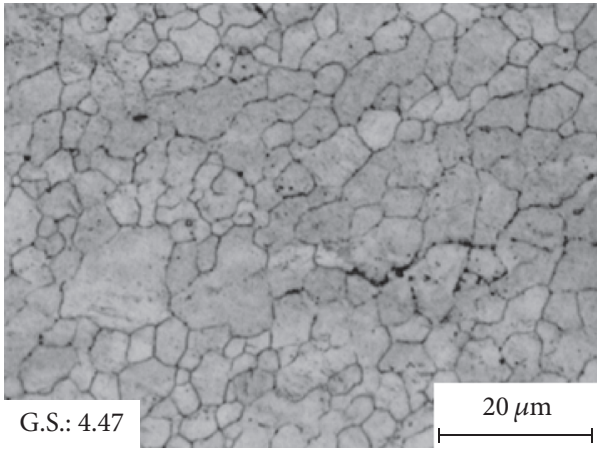

$600 \mathrm{rpm} \_200 \mathrm{~mm} / \mathrm{min}$

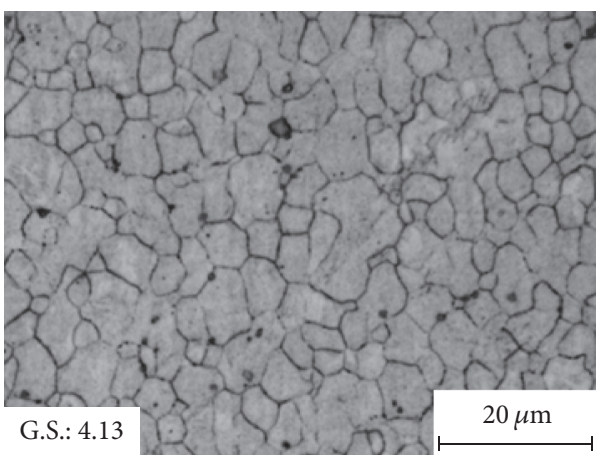

$1200 \mathrm{rpm} \_400 \mathrm{~mm} / \mathrm{min}$
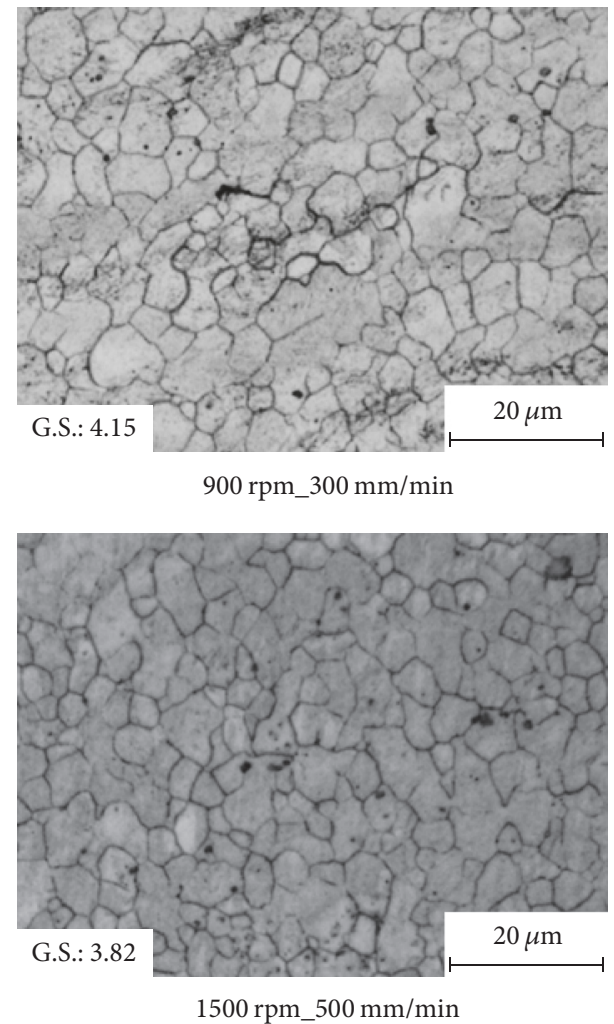

FIgURE 4: Effect of $\omega / \nu$ ratio on stir zone microstructure. G.S. (grain size). 


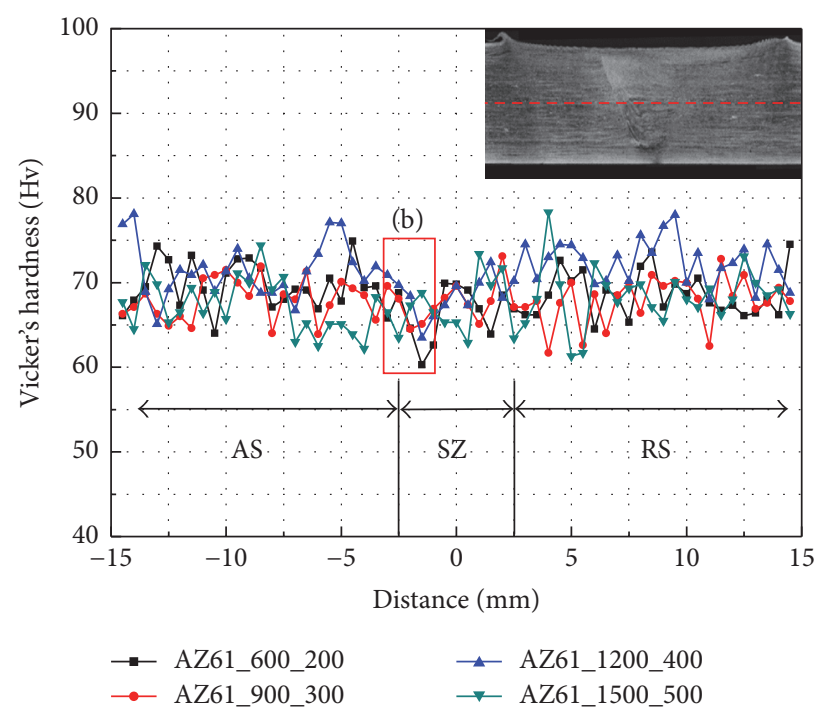

(a)

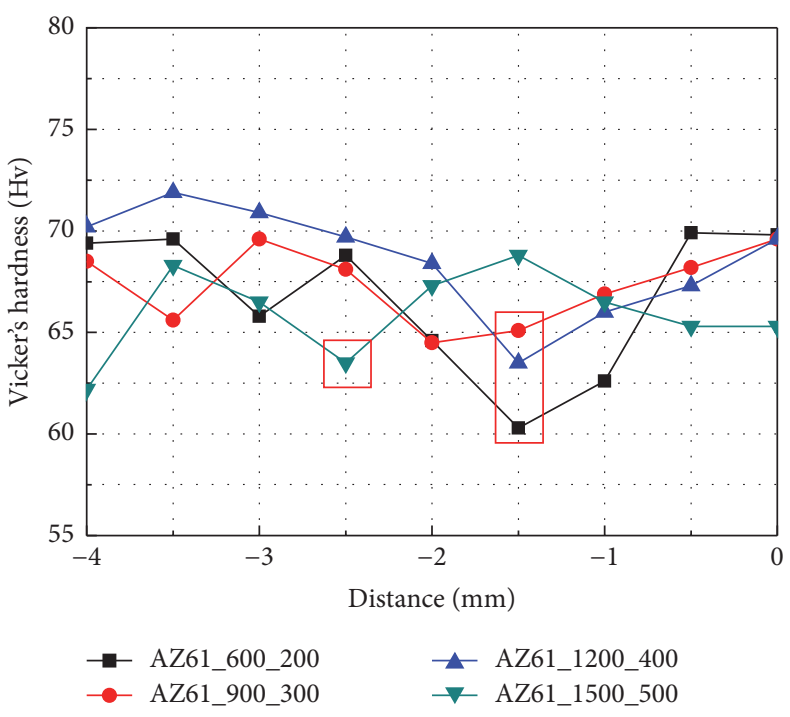

(b)

Figure 5: Typical hardness profiles of cross section welded joint at $\omega / \nu$ ratio of 3.

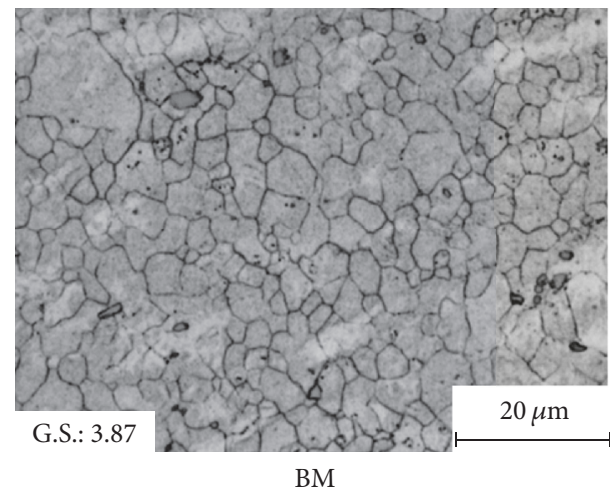

(a)

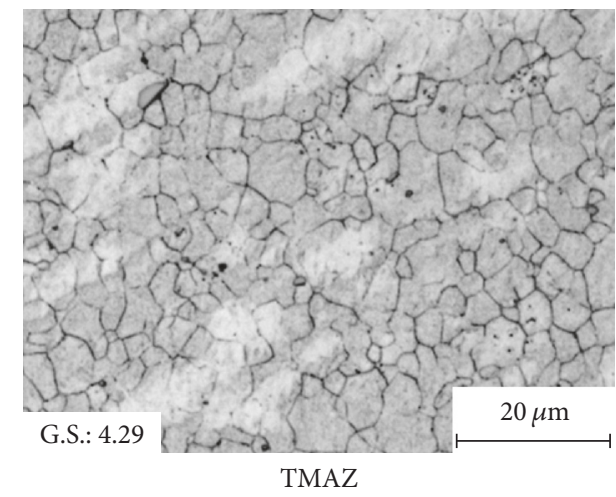

(b)

Figure 6: Microstructures of (a) BM and (b) TMAZ of sample $1500 \mathrm{rpm} \_500 \mathrm{~mm} / \mathrm{min}$.

there were no defects. Therefore, this behavior implies that this region is the weakest location and yet has no defects. These results show the same trend as those in the studies of Afrin et al. [22] and Liu et al. [39] for AZ31 magnesium alloy and 2017 aluminum alloy.

A comparison of the fracture location and the hardness distribution of the specimens is presented in Figure 7. The fracture location of the tensile specimens was found to coincide with the region in which the hardness temporarily decreases. For more detailed analysis, the fracture surface was observed using a scanning electron microscope (SEM). SEM images for the welding conditions of (b) and (h) are presented in Figure 8. Regions (3) and (6) below the fracture surface in Figure 8 are the root parts of the welded regions. Cleavage patterns and dimples were observed in region (6); however region (3) clearly revealed defects confirming the optical microscope (Figure 3). Wavy patterns and partially smooth areas were observed in region (3); these patterns indicate tunnel defects. The wavy pattern is a trace of the welding tool; the smooth areas can be judged as evidence that the materials are not mixed with each other. It is considered that the defect in region (3) served as a catalyst of crack propagation. As a result, the joint involving the defect has a relatively lower elongation; this elongation is on average $3.8 \%$ lower than that of the defect free specimen. Regions (1) and (4) are the upper parts of the welded region. Region (1) mainly consists of cleavage, unlike region (4), in which the dimple shape appears; it was assumed that crack propagation occurred very rapidly in this region. Regions (2) and (5) are the middle part of the stir zone. Since the stirring action was the most active, no defects were found, and dimples were observed. As mentioned above, there was a difference in each region of welding condition (d) and (h) samples. Particularly, in the case of welding condition (h), the fracture surface was irregular as a whole. In the case of welding condition (d), dimples were observed only in region (c), but dimples were observed in all regions of the welding condition (h) sample, and dimples were finer. The size and density of the dimples on 


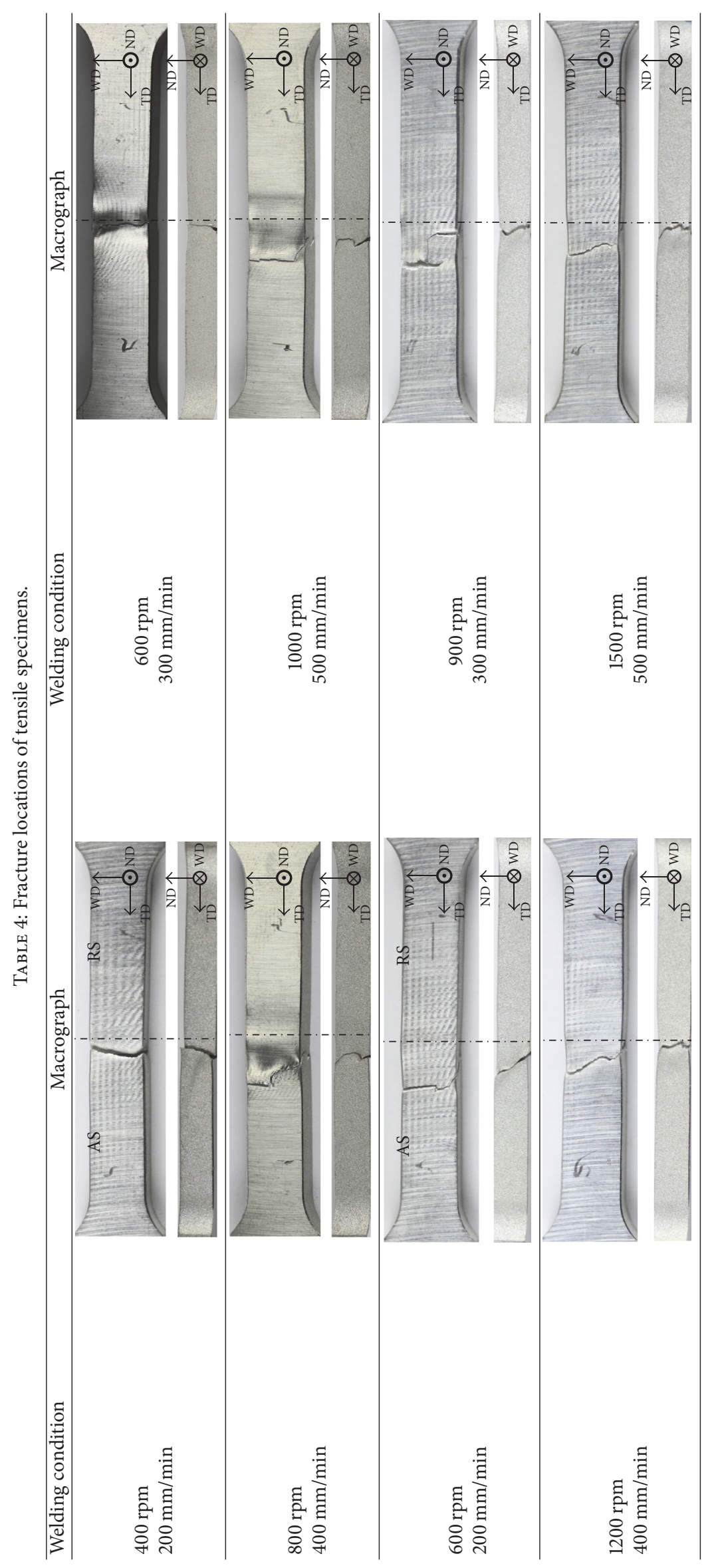




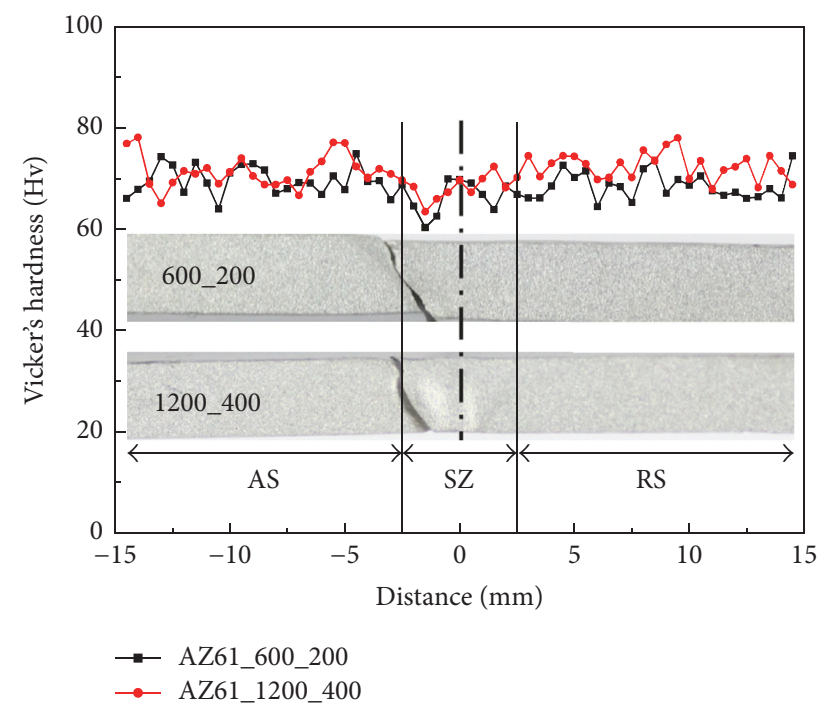

Figure 7: Hardness distribution in cross section of FSW region and cross-sectional view of fracture location.

the fracture surface are related to the strength and ductility of the joint $[40,41]$. Therefore, welding condition (h), including relatively fine dimples, was found to have better mechanical properties than that of the welding condition (d).

3.4. Microtexture. Based on the evaluation of the mechanical properties, and microstructural analysis, the following results were obtained. The relatively weakest regions were revealed to be at the interfaces between the TMAZ and the SZ in the AS region; this behavior showed the same tendency for all welding conditions.

To reveal the cause of the weak mechanical properties at the interface between the SZ and TMAZ grain orientation analysis was used in this section. The mechanical properties depend on the texture variation [42]. If the grain orientation of a weld is examined by electron backscatter diffraction (EBSD) analysis, it can be understood why the hardness temporarily decreases in a specific region of the weld; the cause of fractures in the same region can also be understood. In this EBSD analysis, the step size was $1 \mu \mathrm{m}$; the inverse pole figure (IPF) was calculated based on a scan area of $490 \mu \mathrm{m} \times$ $650 \mu \mathrm{m}$.

The colors of the grains in the IPF map correspond to the crystallographic orientation of the grains; changes in the color mean that the grain orientation has been changed. The IPF maps of welding condition (h) and pole figure (PF) of base material are shown in Figures 9 and 10, respectively. In Figure 9, (1) and (3) show the grain orientations at the AS and retreating side (RS) regions, including the interface between the SZ and the TMAZ; (2) is the SZ. The PF map of the base material shown in Figure 10 also indicates that the (0001) plane is parallel to the normal direction (ND). The color change between the AS and RS regions is clearer than that in the stir zone, as shown in Figure 9. Most of the grains in the stir zone are red, which means that the (0001) plane is parallel to the welding direction (WD). This result contrasts with the grain orientation of the base material. Therefore, it means that the basal poles changed from the ND to the WD in the SZ during the FSW process. This orientation change of the grains has been reported in the literature [42] as a phenomenon caused by a rotating welding tool. In addition, Park et al. [33] have found that texture distribution, grain size, and dislocation density strongly affect the mechanical properties of FSWed of AZ61 magnesium alloy.

Although Figure 9 (1) and (3) show locations at the same distance from the center, the level of color variation at the interface between SZ and TMAZ is obvious. In the case of the AS region, the color variation dramatically changes from blue or green to red, while in the RS region, the color variation gradually changes. In the AS region, because the rotational direction of welding tool matches the $\mathrm{WD}$, a higher plastic flow occurs than that in the RS region [31, 43, 44]. In other words, the plastic flow in the AS and RS regions is asymmetric because friction stir welding is performed only in one rotational direction. As a result, it is considered that the grain orientation variation in the AS region is more dramatic than that in the RS region. The weakest mechanical properties at the interface between the SZ and the AS-TMAZ were found to be the result of asymmetric plastic flow.

\section{Conclusion}

In this study, evaluation of mechanical properties and microstructural analysis of butt-FSWed AZ61 magnesium alloy plate which had fabricated by extrusion was carried out, and the following conclusions were obtained:

(1) The $\omega / v$ ratio of 2 was not suitable for joining the AZ61 magnesium alloy because tunnel defects were observed in the welded region although the yield strength was slightly higher than that obtained using the ratio of 3 . On the other hand, the welded regions for the $\omega / \nu$ ratio of 3 can be inferred to have been applied at proper heat input because no defects, such as large amounts of flash, or tunnel or cavity defects, were observed. As a result, the average joint efficiency satisfying $\omega / \nu$ ratio of 3 was reached up to $100.8 \%$.

(2) In all samples satisfying $\omega / v$ ratios 3 , the hardness tended to decrease slightly between $1 \mathrm{~mm}$ and $3 \mathrm{~mm}$ of AS region temporarily. In addition, in the tensile test, the fracturing of the specimen occurred at a location between 1 and $4 \mathrm{~mm}$ from the center of the weld to the AS region. From these results, it was determined that the failure regions coincided with the regions in which the hardness temporarily decreased. However, as a result of observing the microstructure of TMAZ, the factors of dropping in hardness could not be found. Therefore, it can be inferred that the region where the hardness temporarily decreased is the interface between SZ and TMAZ, and EBSD analysis was required to analyze the grain orientations at that region.

(3) From the result of the EBSD analysis, it was found that the base material usually has a grain orientation with the (0001) plane parallel to the ND; however, the 


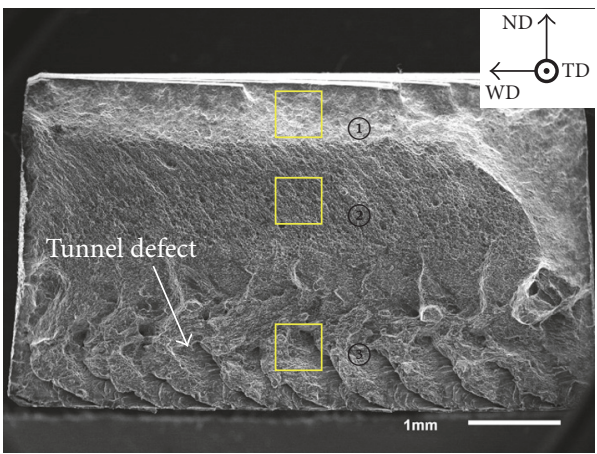

(a)

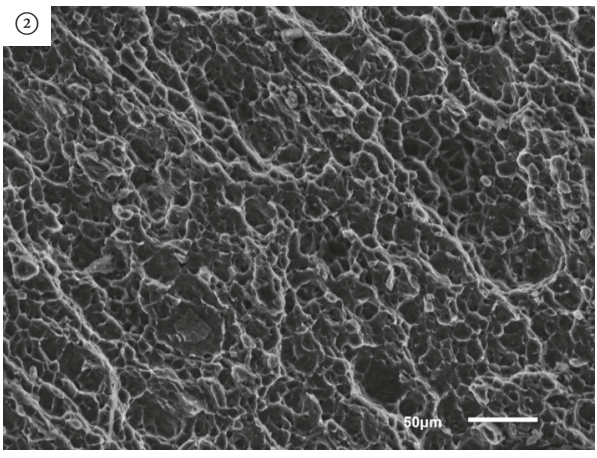

(c)

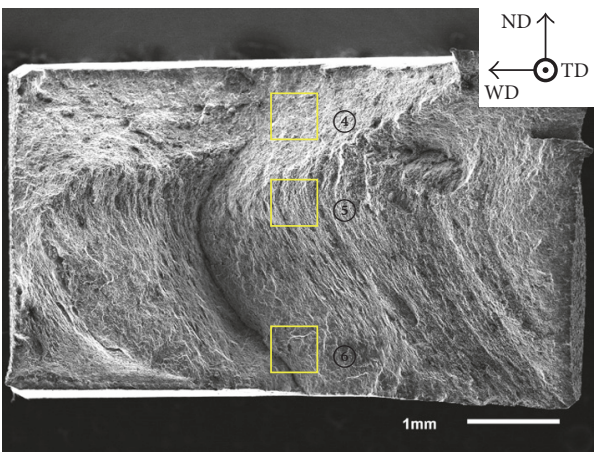

(e)

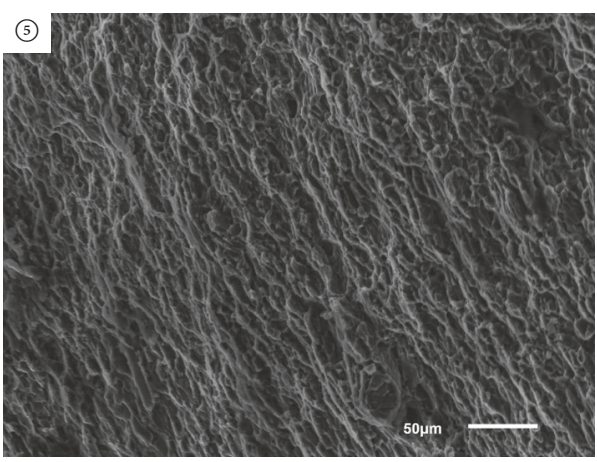

(g)

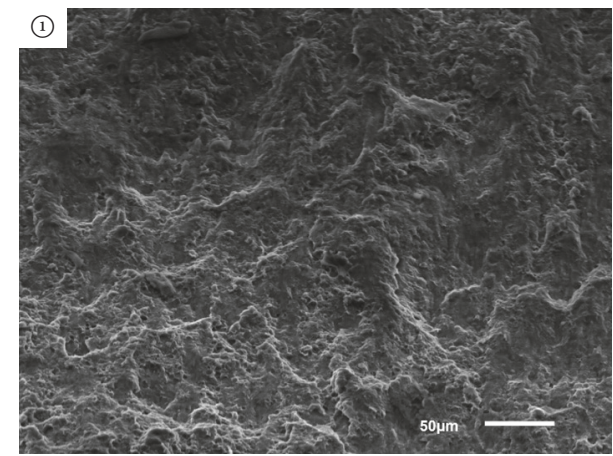

(b)

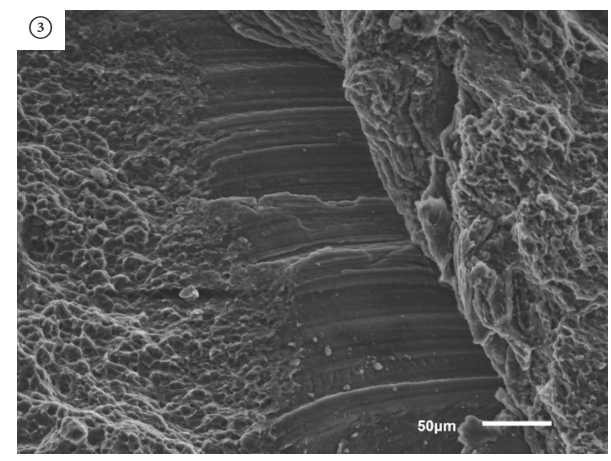

(d)

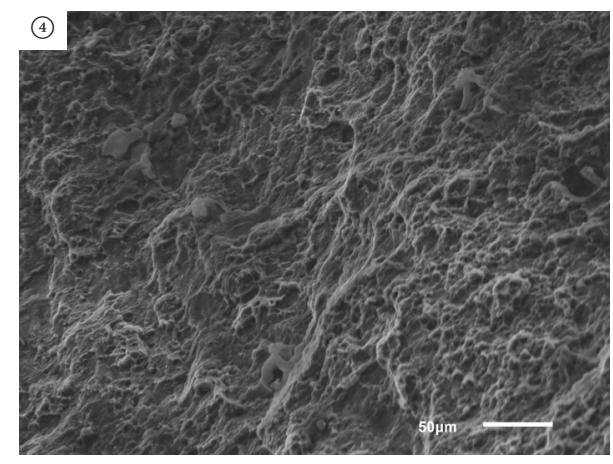

(f)

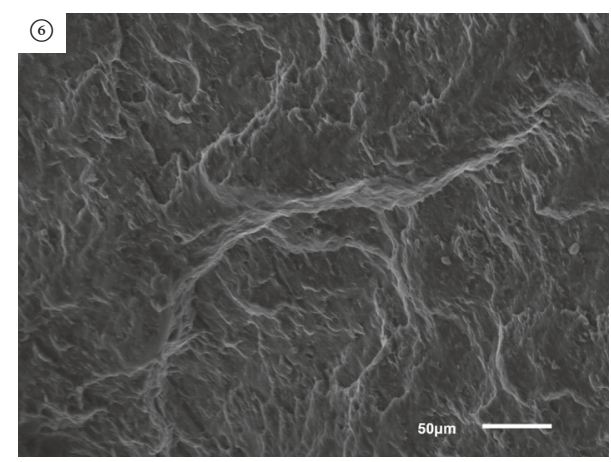

(h)

FIGURE 8: SEM fractographs of samples (a) $600 \mathrm{rpm} \_300 \mathrm{~mm} / \mathrm{min}$ and (e) $1500 \mathrm{rpm} \_500 \mathrm{~mm} / \mathrm{min}$; (b), (c), and (d) magnified micrographs of marked yellow squares in (a), (f), (g), and (h) magnified micrographs of marked yellow squares in (e). 


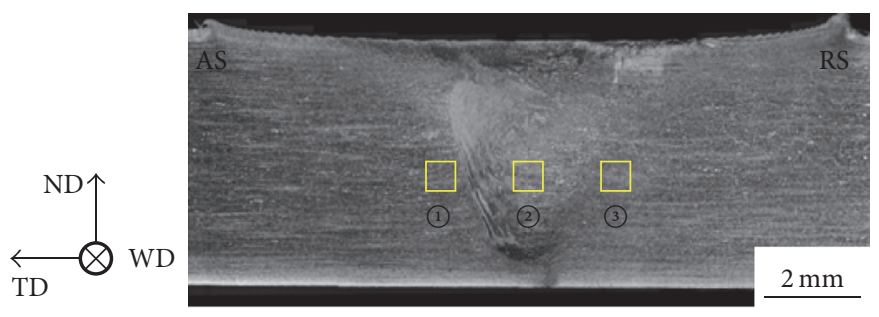

(a)
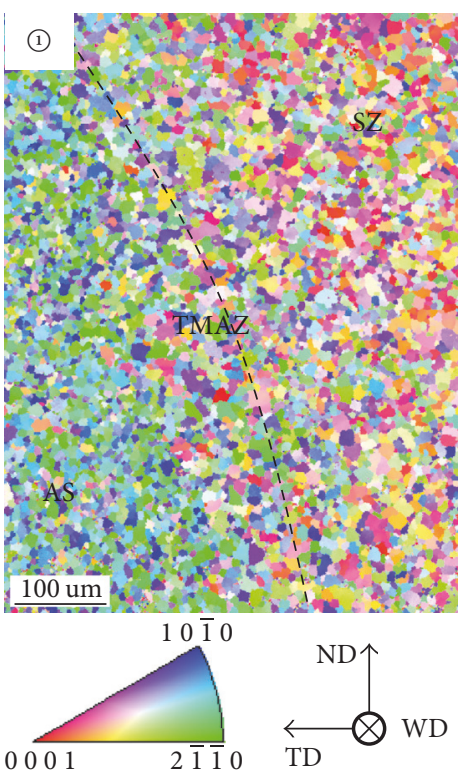

(b)
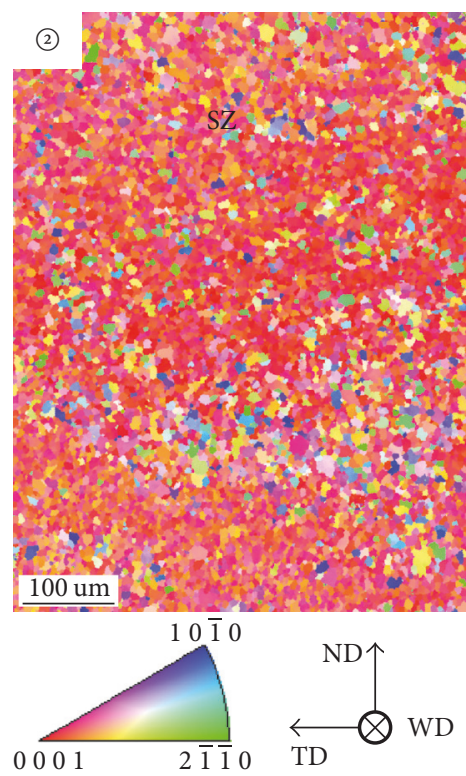

(c)

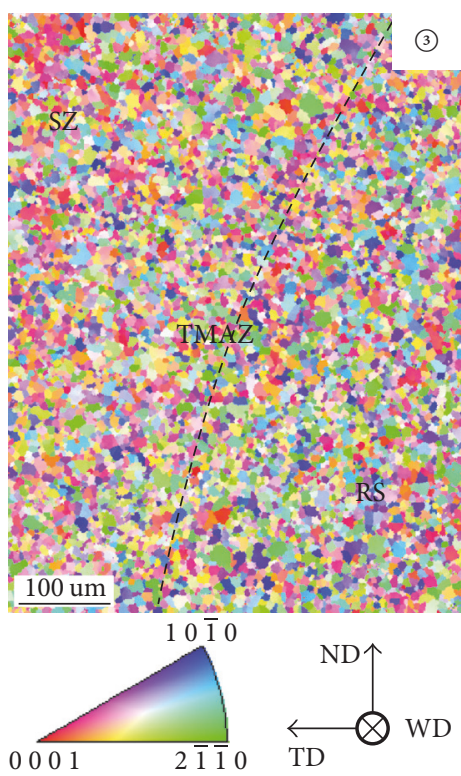

(d)

FIGURE 9: EBSD maps of sample 1500 rpm_500 mm/min; (a) cross-sectional macrographs, (b) AS-TMAZ, (c) SZ, and (d) RS-TMAZ.
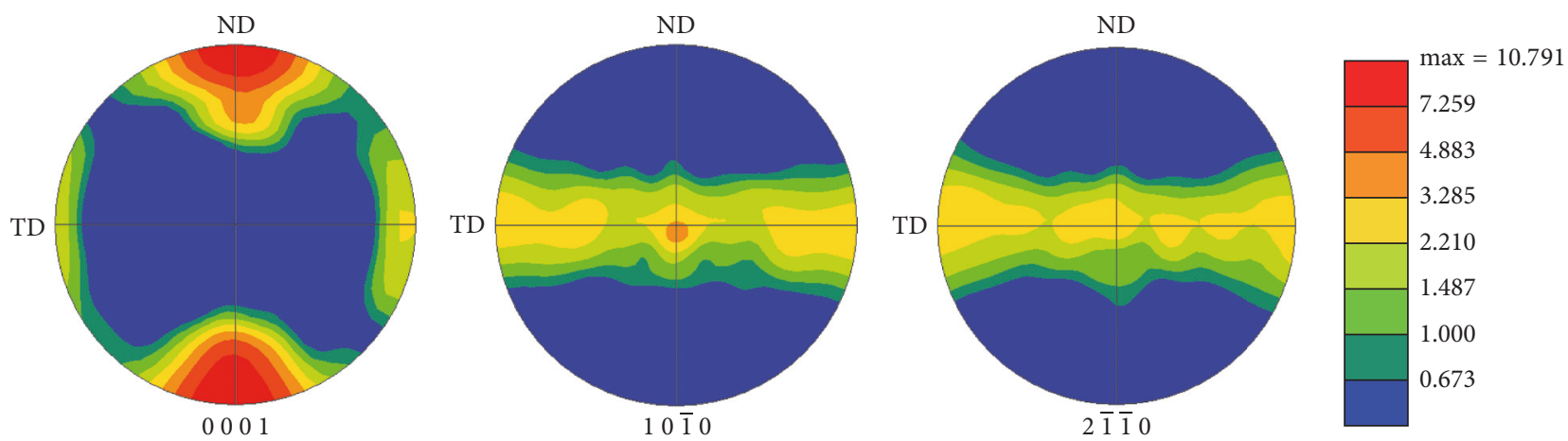

Figure 10: Pole figures of the base material (AZ61 magnesium alloy extruded plate).

(0001) plane in the stir zone was parallel to the WD. Hence, the interface between the TMAZ and the stir zone, where the grain orientation changes, was the weakest. In addition, since the variation of the grain orientation at the interface between AS-TMAZ and SZ was more dramatic than that in the RS region, the AS region was determined to be relatively weaker than the RS region.
(4) The shear plastic flow during friction stir welding process has an influence on the texture variations. In particular, asymmetric plastic flow due to one-way rotation is inevitable. Thus, to improve the mechanical properties of welds, it is necessary to alleviate drastic changes in grain orientation by developing new design welding tools that can change the plastic flow or by controlling welding parameters such as 
down force, rotational speed, and welding speed appropriately. In addition, for the application of the AZ61 magnesium alloy to the structures, it should be considered that the interface between SZ and ASTMAZ is most vulnerable to fracture.

\section{Conflicts of Interest}

The authors declare that there are no conflicts of interest regarding the publication of this paper.

\section{Acknowledgments}

This research was supported by a Grant (PK1702A) from the R\&D program of Korea Railroad Research Institute, Republic of Korea.

\section{References}

[1] S. M. Brückmann, H. E. Friedrich, M. Kriescher, G. Kopp, and R. Gätzi, "Lightweight sandwich structures in innovative vehicle design under crash load cases," Materials Science Forum, vol. 879, pp. 2419-2427, 2017.

[2] B. P. Rochard and F. Schmid, "Benefits of lower-mass trains for high speed rail operations," Proceedings of the Institution of Civil Engineers: Transport, vol. 157, no. 1, pp. 51-64, 2004.

[3] G.-W. Jang, M.-S. Yoon, and J. H. Park, "Lightweight flatbed trailer design by using topology and thickness optimization," Structural and Multidisciplinary Optimization, vol. 41, no. 2, pp. 295-307, 2010.

[4] Q. Li, G. P. Steven, and Y. M. Xie, "Evolutionary structural optimization for stress minimization problems by discrete thickness design," Computers and Structures, vol. 78, no. 6, pp. 769-780, 2000.

[5] C. J. Cameron, E. Lind Nordgren, P. Wennhage, and P. Göransson, "On the balancing of structural and acoustic performance of a sandwich panel based on topology, property, and size optimization," Journal of Sound and Vibration, no. 13, pp. 2677-2698, 2014.

[6] C. J. Cameron, P. Wennhage, P. Göransson, and S. Rahmqvist, "Structural-acoustic design of a multi-functional sandwich panel in an automotive context," Journal of Sandwich Structures and Materials, vol. 12, no. 6, pp. 684-708, 2010.

[7] H. N. G. Wadley, "Multifunctional periodic cellular metals," Philosophical Transactions of the Royal Society A, vol. 364, no. 1838, pp. 31-68, 2006.

[8] A. G. Evans, J. W. Hutchinson, N. A. Fleck, M. F. Ashby, and H. N. G. Wadley, "The topological design of multifunctional cellular metals," Progress in Materials Science, vol. 46, no. 3-4, pp. 309-327, 2001.

[9] M. Hakamada, T. Furuta, Y. Chino, Y. Chen, H. Kusuda, and M. Mabuchi, "Life cycle inventory study on magnesium alloy substitution in vehicles," Energy, vol. 32, no. 8, pp. 1352-1360, 2007.

[10] C. H. Caceres, "Economical and environmental factors in light alloys automotive applications," Metallurgical and Materials Transactions A: Physical Metallurgy and Materials Science, vol. 38, no. 7, pp. 1649-1662, 2007.

[11] R. S. Mishra and Z. Y. Ma, "Friction stir welding and processing," Materials Science and Engineering, vol. 50, no. 1-2, pp. 1-78, 2005.
[12] M. A. Sutton, B. Yang, A. P. Reynolds, and R. Taylor, "Microstructural studies of friction stir welds in 2024-T3 aluminum," Materials Science and Engineering A, vol. 323, no. 1-2, pp. 160166, 2002.

[13] C. J. Dawes and W. M. Thomas, "Friction stir process welds aluminium alloys: The process produces low-distortion, highquality, low-cost welds on aluminium," Welding Journal, vol. 75, no. 3, pp. 41-45, 1996.

[14] B. Çevik, Y. Özçatalbas, and B. Gülenç, "Effect of welding speed on the mechanical properties and weld defects of 7075 Al alloy joined by FSW," Kovove Materialy, vol. 54, no. 4, pp. 241-247, 2016.

[15] A.-M. El-Batahgy, T. Miura, R. Ueji, and H. Fujii, "Investigation into feasibility of FSW process for welding 1600MPa quenched and tempered steel," Materials Science and Engineering A, vol. 651, pp. 904-913, 2016.

[16] A. S. Sedmak, R. Kumar, S. Chattopadhyaya et al., "Heat input effect of friction stir welding on aluminum alloy AA 6061-T6 welded joint," Thermal Science, vol. 20, no. 2, pp. 637-641, 2016.

[17] G. Padmanaban and V. Balasubramanian, "Selection of FSW tool pin profile, shoulder diameter and material for joining AZ31B magnesium alloy-an experimental approach," Materials and Design, vol. 30, no. 7, pp. 2647-2656, 2009.

[18] Y. Gao, K. Nakata, K. Nagatsuka, T. Matsuyama, Y. Shibata, and M. Amano, "Microstructures and mechanical properties of friction stir welded brass/steel dissimilar lap joints at various welding speeds," Materials and Design, vol. 90, pp. 1018-1025, 2016.

[19] K. P. Mehta and V. Badheka, "Experimental Investigation of Process Parameters on Defects Generation in Copper to AA6061-T651 Friction Stir Welding," International Journal of Advances in Mechanical \& Automobile Engineering, vol. 3, no. 1, pp. 55-58, 2016.

[20] Y. G. Kim, H. Fujii, T. Tsumura, T. Komazaki, and K. Nakata, "Three defect types in friction stir welding of aluminum die casting alloy," Materials Science and Engineering A, vol. 415, no. 1-2, pp. 250-254, 2006.

[21] T. Yoon, S. Park, S. Chung, J. Noh, K. Kim, and C. Kang, "Effect of surface oxidation layer on tensile strength of $\mathrm{Cu}-\mathrm{Ni}$ alloy in friction stir welding," Metals and Materials International, vol. 22, no. 3, pp. 501-508, 2016.

[22] N. Afrin, D. L. Chen, X. Cao, and M. Jahazi, "Microstructure and tensile properties of friction stir welded AZ31B magnesium alloy," Materials Science and Engineering A, vol. 472, no. 1-2, pp. 179-186, 2008.

[23] O. Frigaard, O. Grong, and B. Bjorneklett, "Midling OT, in Proceedings of the 1st International Symposium on Friction Stir Welding, Thousand Oaks, Calif, USA, 1999.

[24] M. S. Moghaddam, R. Parvizi, M. Haddad-Sabzevar, and A. Davoodi, "Microstructural and mechanical properties of friction stir welded $\mathrm{Cu}-30 \mathrm{Zn}$ brass alloy at various feed speeds: Influence of stir bands," Materials and Design, vol. 32, no. 5, pp. 2749-2755, 2011.

[25] Investigations on friction stir welding of AZ61A magnesium alloy [Ph.D. thesis], University of Anna, Chennai, India, 2012.

[26] R. Nandan, T. DebRoy, and H. K. D. H. Bhadeshia, "Recent advances in friction-stir welding-process, weldment structure and properties," Progress in Materials Science, vol. 53, no. 6, pp. 980-1023, 2008.

[27] Z. W. Chen, T. Pasang, and Y. Qi, "Shear flow and formation of Nugget zone during friction stir welding of aluminium alloy 
5083-O," Materials Science and Engineering A, vol. 474, no. 1-2, pp. 312-316, 2008.

[28] G. M. Xie, Z. Y. Ma, and L. Geng, "Development of a finegrained microstructure and the properties of a nugget zone in friction stir welded pure copper," Scripta Materialia, vol. 57, no. 2, pp. 73-76, 2007.

[29] T. Hirata, T. Oguri, H. Hagino et al., "Influence of friction stir welding parameters on grain size and formability in 5083 aluminum alloy," Materials Science and Engineering A, vol. 456, no. 1-2, pp. 344-349, 2007.

[30] S. H. C. Park, Y. S. Sato, and H. Kokawa, "Microstructural evolution and its effect on Hall-Petch relationship in friction stir welding of thixomolded Mg alloy AZ91D," Journal of Materials Science, vol. 38, no. 21, pp. 4379-4383, 2003.

[31] M. Abbasi Gharacheh, A. H. Kokabi, G. H. Daneshi, B. Shalchi, and R. Sarrafi, "The influence of the ratio of "rotational speed/traverse speed" ( $\omega / \mathrm{v})$ on mechanical properties of AZ31 friction stir welds," International Journal of Machine Tools and Manufacture, vol. 46, no. 15, pp. 1983-1987, 2006.

[32] W. D. Callister Jr. and D. G. Rethwisch, Materials Science and Engineering: An Introduction, John Wiley sons, Inc, Hoboken, NJ, USA, 7th edition, 2007.

[33] S. H. C. Park, Y. S. Sato, and H. Kokawa, "Effect of micro-texture on fracture location in friction stir weld of Mg alloy AZ61 during tensile test," Scripta Materialia, vol. 49, no. 2, pp. 161-166, 2003.

[34] S. S. Sabari, S. Malarvizhi, and V. Balasubramanian, "Influences of tool traverse speed on tensile properties of air cooled and water cooled friction stir welded AA2519-T87 aluminium alloy joints," Journal of Materials Processing Technology, vol. 237, pp. 286-300, 2016.

[35] Z. Zhang, B. L. Xiao, and Z. Y. Ma, "Effect of welding parameters on microstructure and mechanical properties of friction stir welded 2219Al-T6 joints," Journal of Materials Science, vol. 47, no. 9, pp. 4075-4086, 2012.

[36] S. R. Ren, Z. Y. Ma, and L. Q. Chen, "Effect of welding parameters on tensile properties and fracture behavior of friction stir welded Al-Mg-Si alloy,' Scripta Materialia, vol. 56, no. 1, pp. 6972, 2007.

[37] W.-B. Lee, Y.-M. Yeon, and S.-B. Jung, "Mechanical properties related to microstructural variation of $6061 \mathrm{Al}$ alloy joints by friction stir welding," Materials Transactions, vol. 45, no. 5, pp. 1700-1705, 2004.

[38] J. Yang, D. Wang, B. L. Xiao, D. R. Ni, and Z. Y. Ma, "Effects of rotation rates on microstructure, mechanical properties, and fracture behavior of friction stir-welded (FSW) AZ31 magnesium alloy," Metallurgical and Materials Transactions A: Physical Metallurgy and Materials Science, vol. 44, no. 1, pp. 517530, 2013.

[39] H. J. Liu, H. Fujii, M. Maeda, and K. Nogi, “Tensile properties and fracture locations of friction-stir-welded joints of 2017-T351 aluminum alloy," Journal of Materials Processing Technology, vol. 142, no. 3, pp. 692-696, 2003.

[40] T. S. Srivatsan, S. Vasudevan, and L. Park, “The tensile deformation and fracture behavior of friction stir welded aluminum alloy 2024," Materials Science and Engineering A, vol. 466, no. 1-2, pp. 235-245, 2007.

[41] D. C. Lin, G.-X. Wang, and T. S. Srivatsan, "A mechanism for the formation of equiaxed grains in welds of aluminum-lithium alloy 2090," Materials Science and Engineering A, vol. 351, no. 1-2, pp. 304-309, 2003.

[42] W. Woo, H. Choo, D. W. Brown, P. K. Liaw, and Z. Feng, "Texture variation and its influence on the tensile behavior of a friction-stir processed magnesium alloy," Scripta Materialia, vol. 54, no. 11, pp. 1859-1864, 2006.

[43] H. W. Zhang, Z. Zhang, and J. T. Chen, "The finite element simulation of the friction stir welding process," Materials Science and Engineering A, vol. 403, no. 1-2, pp. 340-348, 2005.

[44] Y. Li, L. E. Murr, and J. C. McClure, "Solid-state flow visualization in the friction-stir welding of $2024 \mathrm{Al}$ to $6061 \mathrm{Al}$," Scripta Materialia, vol. 40, no. 9, pp. 1041-1046, 1999. 

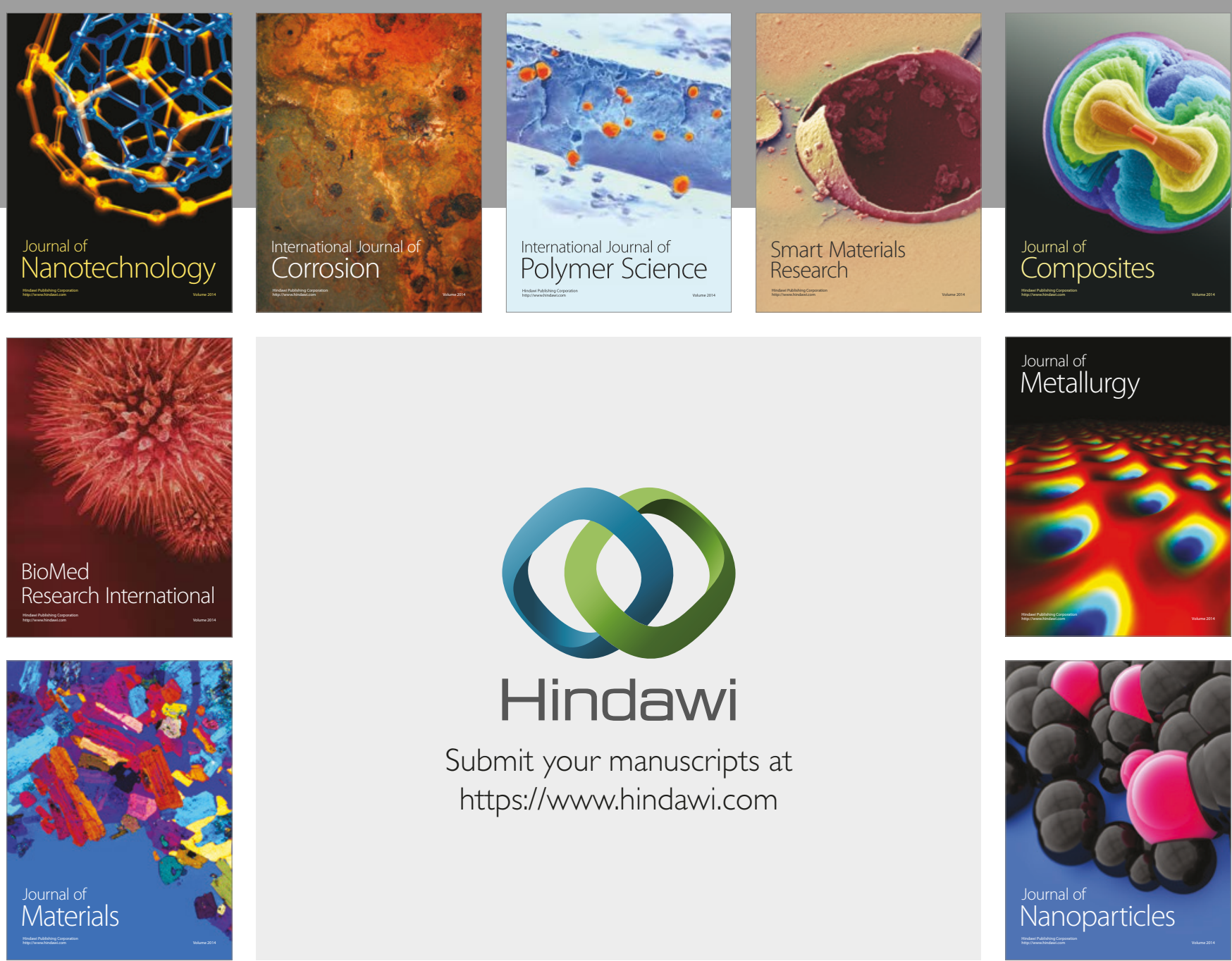

\section{Hindawi}

Submit your manuscripts at

https://www.hindawi.com
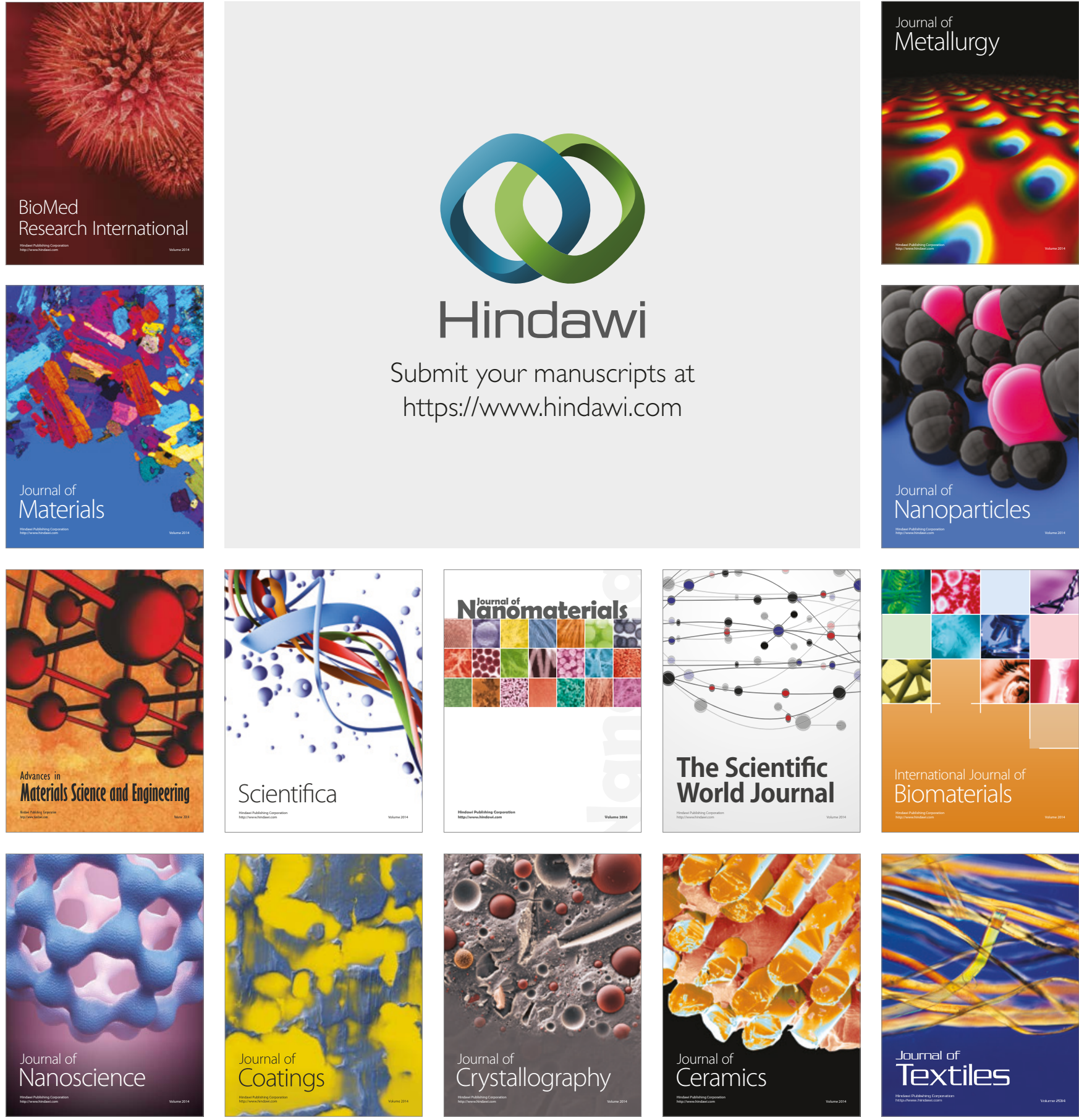

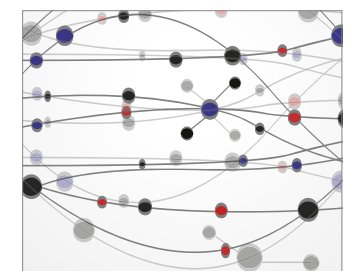

The Scientific World Journal
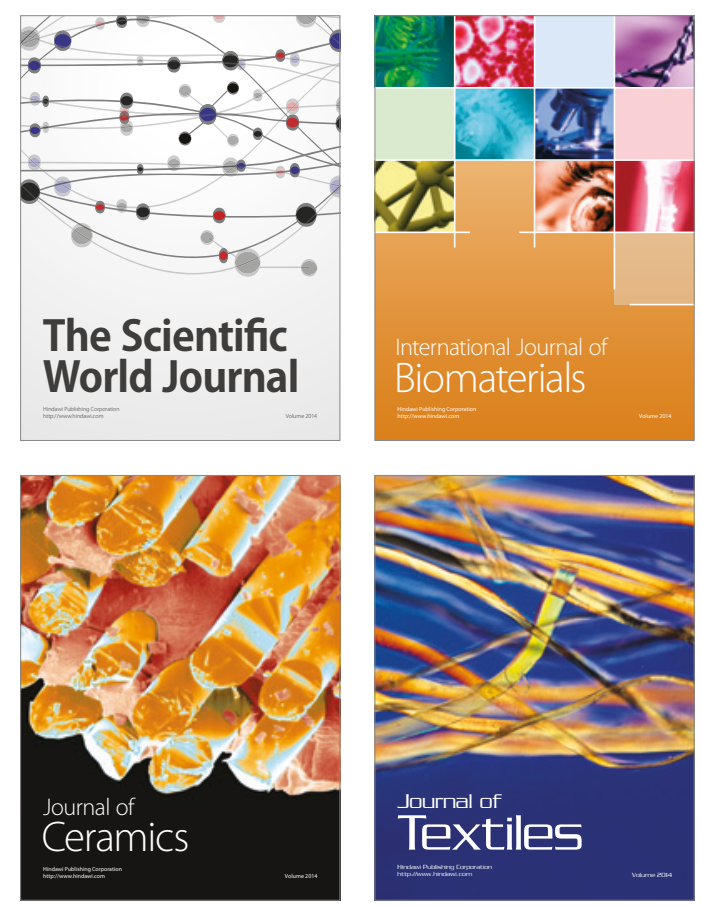